Chinese Journal of Organic Chemistry

\title{
烯烃氢氯化反应的研究进展
}

\author{
王耀金金崔 晨杨小会* \\ (北京理工大学前沿交叉科学研究院＼cjkstart化学与化工学院＼cjkstart北京 100081)
}

\begin{abstract}
摘要 有机氯化物已经被广泛应用到医药、农药及材料等领域. 此外, 有机氯化物也是重要的合成砌块, 作为起始原料 参与到多种反应中，例如自由基反应、取代反应以及偶联反应等. 烯烃的氢氯化反应是合成有机氯化物最直接高效的 方法之一, 在过去三十年已经取得了很多突破性的成果. 系统介绍了近三十年烯烃氢氯化反应的研究进展, 按照是否 涉及金属催化，主要分为无金属参与的氢氯化反应和金属催化的氢氯化反应. 分别着重介绍了其相应的反应类型及相 关机理，并对今后的发展方向进行了展望.

关键词 烯烃; 氢氯化反应; 氯化氢; 有机氯化物; 金属催化
\end{abstract}

\section{Recent Advances in Hydrochlorination of Alkenes}

\author{
Wang, Yaoxin Cui, Chen Yang, Xiaohui* \\ (Advanced Research Institute of Multidisciplinary Science, School of Chemistry and Chemical Engineering, \\ Beijing Institute of Technology, Beijing 100081)
}

\begin{abstract}
Organochlorides have been widely used in medicine, pesticides, materials and other fields. In addition, organochlorides are also important synthetic building blocks. They have participated in a variety of reactions, such as free radical reactions, substitution reactions and cross-coupling reactions. The hydrochlorination of olefins is one of the most direct and efficient methods for the synthesis of organochlorides, and remakable breakthroughs have been made in the past thirty years. The research progress of olefin hydrochlorination in the past three decades is introduced. According to whether metal catalysis is involved, it is mainly classified into two categories: metal-free alkene hydrochlorination and metal-catalyzed alkene hydrochlorination. Different type of hydrochlorination reactions and related mechanisms are summarized. In addition, the future development direction of alkene hydrochlorination is prospected.

Keywords alkene; hydrochlorination; hydrogen chloride; organochloride; metal catalysis
\end{abstract}

\section{Introduction}

Organochlorides are widely used in industry, agriculture and domestic technology. Moreover, they are also invaluable synthons for further chemistry, particularly in free radical reactions, ${ }^{[1]}$ nucleophilic substitution reactions ${ }^{[2]}$ and cross-coupling reactions. ${ }^{[3]}$ Various approaches have been developed to synthesize organochlorides, such as substitution, ${ }^{[4]}$ reduction of alkenyl chlorides, ${ }^{[5]}$ hydrochlorination of alkynes ${ }^{[6]}$ and chlorination through $\mathrm{C}-\mathrm{H}$ activation. ${ }^{[7]}$ Among them, the hydrochlorination of alkenes represents one of the most straightforward and atom-economic ways to synthesize alkyl chlorides.

As one of the most fundamental reactions, hydrochlorination of alkenes has been widely studied for over a century. ${ }^{[8]}$ Various methods have been developed to realize this transformation, which could be classified in several ways. On the basis of metal-catalyst involved in the reactions, this transformation can be classified into two main categories: metal-free alkene hydrochlorination and metalcatalyzed alkene hydrochlorination (Scheme 1). In this review, the development of this transformation in the latest 30 years is summarized. The different synthetic methods throughout the years will be described and discussed.

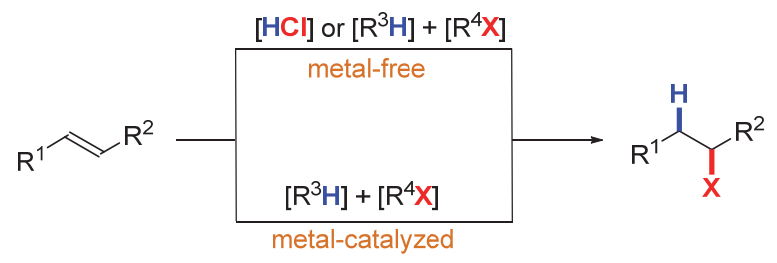

Scheme 1 General methodologies for hydrochlorination of alkenes

\footnotetext{
* Corresponding author. E-mail: xhyang@bit.edu.cn

Received May 31, 2021; revised July 29, 2021; published online August 17, 2021.

Dedicated to the 100th anniversary of Chemistry at Nankai University.
} 


\section{Metal-free hydrochlorination of alkenes}

\subsection{Markovnikov hydrochlorination of alkenes}

One of the earliest alkenes hydrochlorination is the using of gaseous or liquefied $\mathrm{HCl}^{\left[{ }^{[9]}\right.}$ Due to sufficient operational difficulties and low yields, a number of alternatives have been developed. Silica gel or alumina as excellent medium always works as a mild catalyst for some organic transformations. For example, they have been applied for Friedel-Crafts-type nitration of arenes, ${ }^{[10]}$ allylation of aldehydes with tetra-allyltin ${ }^{[11]}$ and Horner-WadsworthEmons reactions. ${ }^{[12]}$

In 1990 and 1993, Kropp and co-workers ${ }^{[13]}$ reported surface-mediated hydrochlorination to increase the reactivity. No target product was detected by treatment of cycloheptene (1) with a saturated solution of $\mathrm{HCl}$ (Scheme 2). Interestingly, the deserved chlorocycloheptane (2) was formed rapidly in $62 \%$ yield with the simple addition of silica gel to the solution. Even more conveniently, simply adding an $\mathrm{HCl}$ precursor such as $\mathrm{SOCl}_{2}$ and $(\mathrm{COCl})_{2}$ to a solution of cycloheptene (1) containing a suspension of silica gel gave chloride 2 rapidly and in high yield. In their report, the hydrogen halide was formed via hydrolysis of the active halides by surface-bound water on the silica gel.

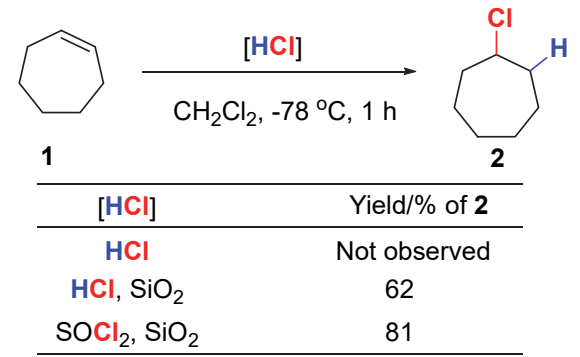

Scheme 2 Silica gel mediated hydrochlorination cycloheptene

Besides silica gel, alumina is also efficient medium to promote the hydrochlorination. As shown in Scheme 3, by using 1-octene (3) as starting material, the deserved chloride product 4 was obtained in $60 \%$ and $86 \%$ yields with the addition of alumina into $\mathrm{HCl}$ or $\mathrm{HCl}$ precursor $\left(\mathrm{COCl}_{2}\right)$.

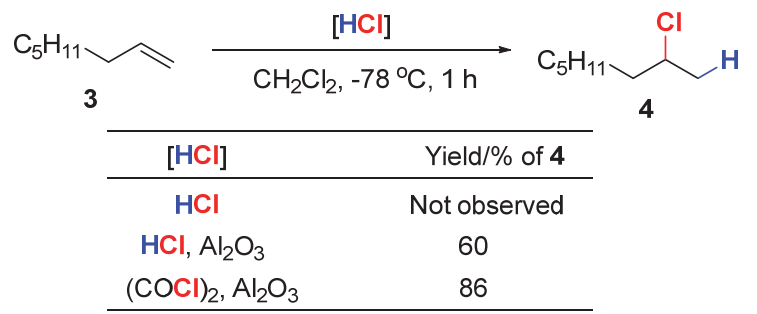

Scheme 3 Alumina mediated hydrochlorination of 1-octene

The use of various $\mathrm{HCl}$ precursors in conjunction with silica or alumina was a convenient method for in situ generation of hydrogen chloride, which avoided the use of gaseous or liquefied $\mathrm{HCl}$. For the mechanism, they believed that silica gel and alumina surfaces presumably promoted ionic addition through hydrogen-bonding interactions, which polarized the $\mathrm{HCl}$ bond and reduced entropy effects by bringing the two reactants together (Scheme 4).

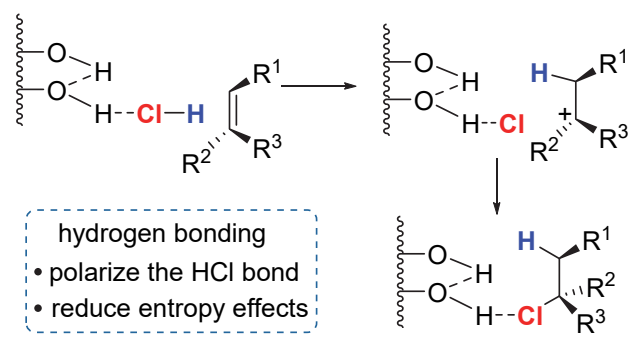

Scheme 4 Mechanism of silica gel or alumina mediated alkene hydrochlorination

By using this method, de Mattos and coworkers ${ }^{[14]}$ reported the hydrochlorination of limonene (5) without the direct use of $\mathrm{HCl}$ in 2001. Using heterogeneous media $\mathrm{SOCl}_{2} / \mathrm{SiO}_{2} / \mathrm{CH}_{2} \mathrm{Cl}_{2}$ at room temperature, the corresponding chloride 6 was obtained in $83 \%$ yield without extensive racemization (Scheme 5). This reaction conditions are much simpler compared with using dry $\mathrm{HCl}$, which usually leads to rearrangement, polymerization or racemization.

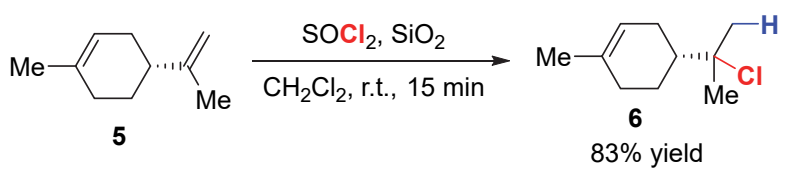

Scheme 5 Hydrochlorination of $(R)$-limonene using $\mathrm{SOCl}_{2} / \mathrm{SiO}_{2}$

While the reactivity can be improved by using $\mathrm{HCl}$ precursor $(\mathrm{COCl})_{2}$ and $\mathrm{SOCl}_{2}$ mediated by silica gel or alumina, highly toxic $\mathrm{CO}$ and $\mathrm{SO}_{2}$ were formed, respectively. In 2018, Tanemura ${ }^{[15]}$ reported silica gel-mediated hydrochlorination of alkenes using hydrochloric acid as the $\mathrm{HCl}$ source. They have examined hydrochlorination of various alkenes with $35 \%$ hydrochloric acid in the presence of silica gel at room temperature (Scheme 6). Terminal (7a),

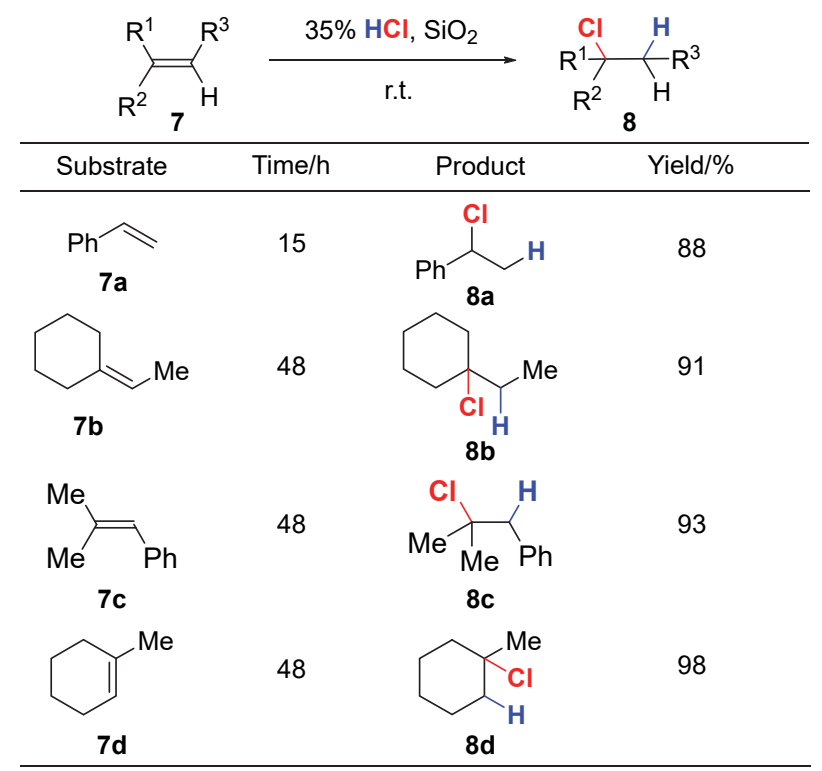

Scheme 6 Silica-gel mediated hydrochlorination of unactivated alkenes by using $35 \%$ hydrochloric acid 
internal (7b, 7c) and cyclic (7d) alkenes were converted into the corresponding chlorides in good yields with great regioselectivity according to Markovnikov's rule. They found that the terminal alkenes reacted faster compared with internal ones.

This transformation showed great chemoselectivity when using substrate containing multiple double bonds. For example, hydrochlorination of $(R)$-carvone $(9)$ provided the chloride $\mathbf{1 0}$ in $83 \%$ yield with the addition of $\mathrm{HCl}$ at the terminal double bond according to Markovnikov's rule, and no addition of $\mathrm{HCl}$ to the enone was observed (Scheme 7).

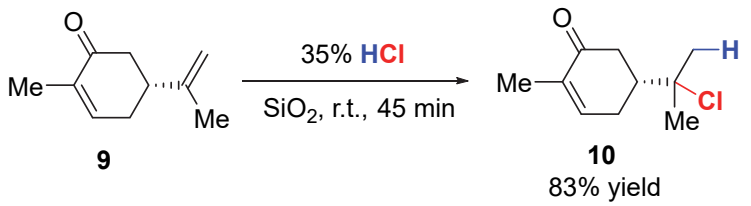

Scheme 7 Hydrochlorination of $(R)$-carvone with great chemoselectivity and regioselectivity

Using silica gel or alumina as medium provides simple and efficient approaches for facilitating addition of $\mathrm{HCl}$ to alkenes for a long time. However, longer reaction time, requirement for chromatographic purification and poor functional group tolerance limit the applications. Moreover, the medium is hard to be recycled without significant loss of activities. Considering this, chemists have developed alternative ways to facilitate the alkene hydrochlorination.

Boudjouk and coworkers developed the hydrochlorination of various alkenes by using a mixture of trimethylchlorosilane and water. Markovnikov addition products (12a and 12b) were obtained with high reactivity and regioselectivity when using unactivated alkenes, and the reaction went through electrophilic addition (Scheme 8). When using $\alpha, \beta$-unsaturated ketone or ester as starting materials, however, only linear organochlorides (12c and 12d) were provided with nucleophilic addition as the mechanism. ${ }^{[16]}$
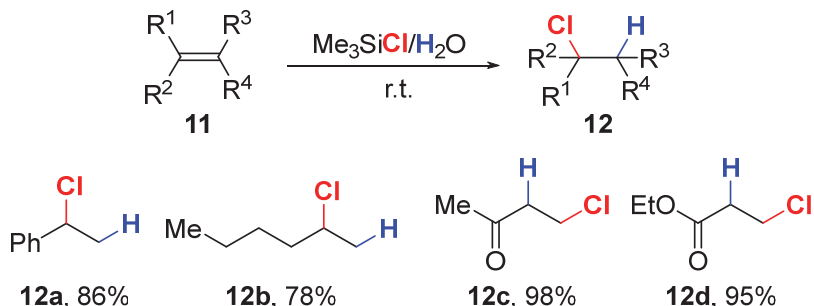

Scheme 8 Hydrochlorination with trimethylchlorosilane and water

In 2005, Yadav and coworkers ${ }^{[17]}$ reported the Markovnikov hydrochlorination of olefins using combination of $\mathrm{AcCl} / \mathrm{EtOH}$, which formed $\mathrm{HCl}$ in situ. Hydrochlorination of mono-, di-, tri- and tetra-substituted alkenes (11a, 11e 11g) provided the corresponding chloride products with excellent yields in an operationally convenient procedure (Scheme 9). The products were isolated with high purity simply by removal of the volatile components under re- duced pressure, and chromatographic purification was not necessary. The amount of EtOH used in the reaction had a significant influence on the reactivity. A possible reason why excess EtOH slows down the reactivity is that electrophilicity of proton is reduced due to solvation by EtOH.

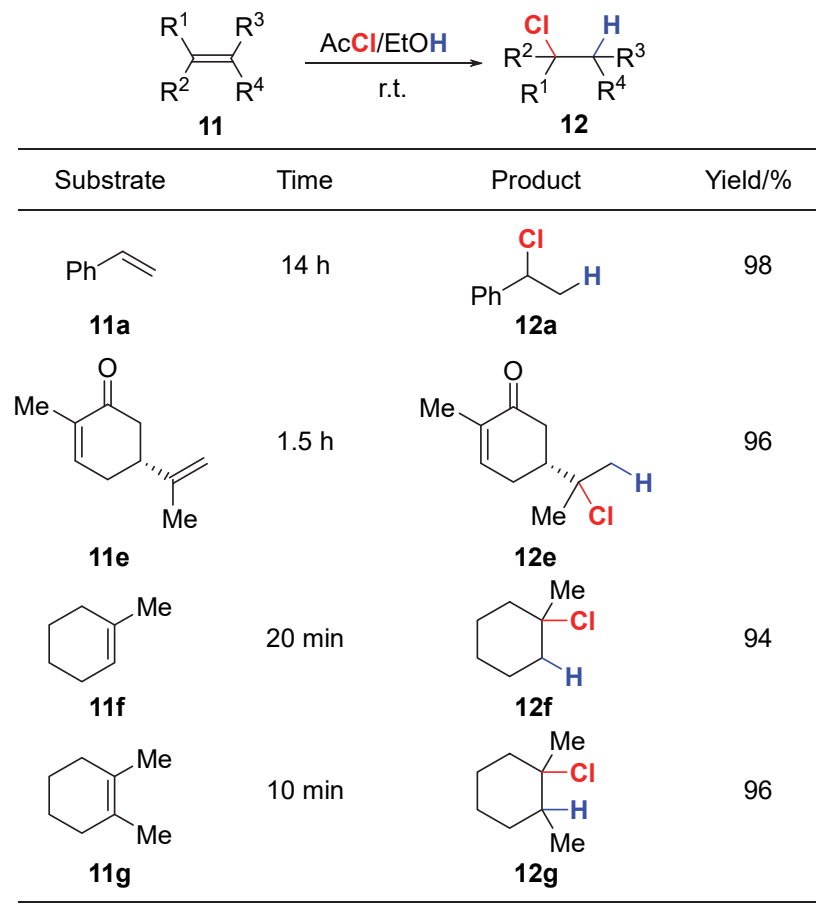

Scheme 9 Markovnikov hydrochlorination of olefins with $\mathrm{AcCl} / \mathrm{EtOH}$

In 2018, Xu and coworkers ${ }^{[18]}$ reported an efficient alkene hydrochlorination using a combined acid $\mathrm{HCl} / \mathrm{DMPU}-$ acetic acid catalytic system, and a wide range of unactivated alkenes can be transformed into the desired chlorides in high yields (Scheme 10). Styrene derivatives $\mathbf{1 4 a} \sim \mathbf{1 4 e}$ underwent the reaction smoothly to give hydrochlorination

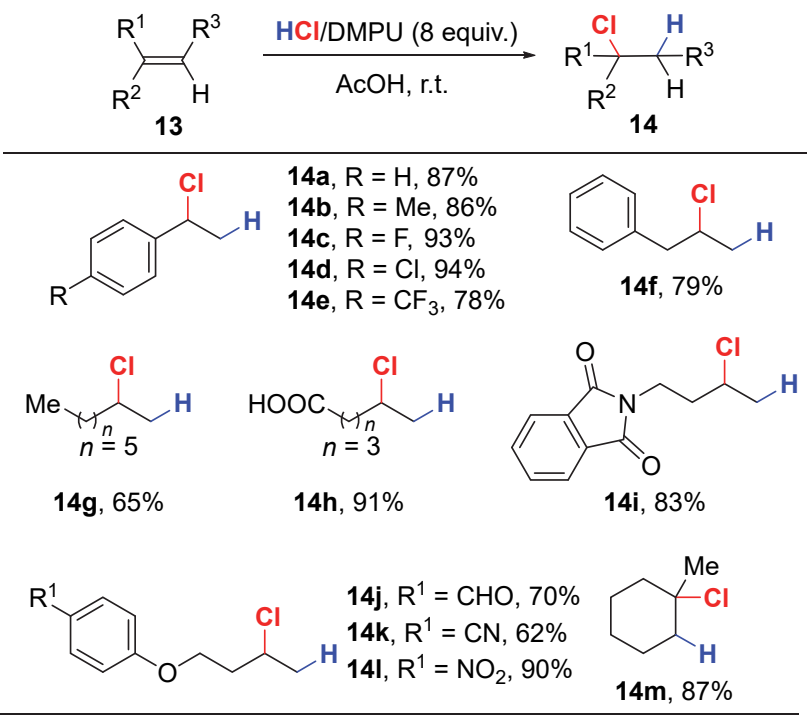

Scheme 10 Hydrochlorination of alkenes with $\mathrm{HCl} / \mathrm{DMPU}$ 
products in high yields at room temperature. Alkyl substituted alkenes were also efficiently converted to the corresponding chlorinated products $(\mathbf{1 4 f}, \mathbf{1 4 g})$. The hydrochlorination tolerated a wide range of functional group such as carboxylic acid (14h), imide (14i), aldehyde $(\mathbf{1 4 j})$, cyano (14k) and nitro (14l).

Although these hydrochlorination reactions with solid surface-promotion or in situ generation of $\mathrm{HCl}$ from highly reactive chlorides provide efficient way to synthesize organochlorine compounds, there are still limitations with a number of substrate classes that possess acid-sensitive moieties, leaving groups and polyenes prone to cyclization. Moreover, these transformations are also challenging when conducted on a small scale. To address these issues, The Synder group ${ }^{[19]}$ developed a novel chlorophosphonium pre-reagents (15 and 16), which were readily synthesized and handled (Scheme 11).

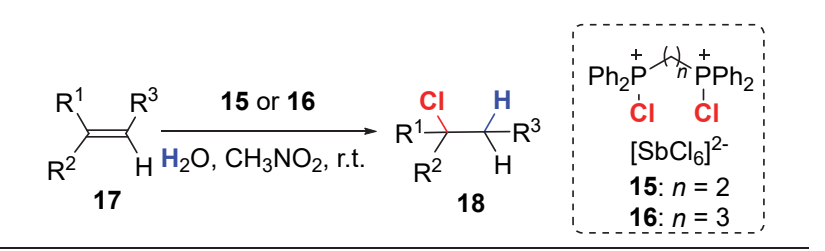<smiles>C#CCCC(=O)OCCC(C)(C)CCl</smiles>

15: $67 \%$; $16: 75 \%$<smiles>CC(C)(C)C(CCn1ccc2cc(Br)ccc21)C(C)(C)Cl</smiles>

15: $47 \%$; $16: 62 \%$<smiles>CC(C)(Cl)CCOC(=O)c1cccs1</smiles>

15: $80 \%$; $16: 85 \%$<smiles>C/C=C\CCC(=O)OCCC(C)(C)Cl</smiles><smiles>CC(Cl)(CCl)CCOCc1ccccc1</smiles>

15: $84 \% ; \quad 16: 87 \%$

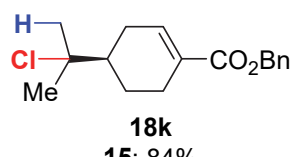

15: $84 \%$

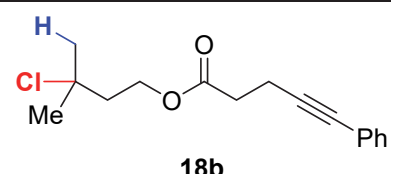

15: $86 \%$

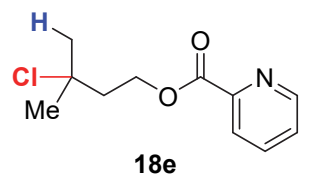

15: $88 \% ; 16$ : $85 \%$

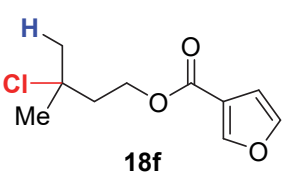

15: $80 \% ; 16: 84 \%$

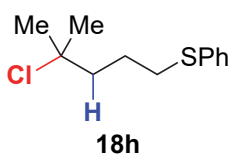

15: $62 \% ; 16: 57 \%$

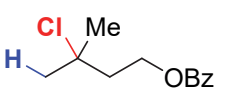

18j

15: $80 \%$; $16: 84 \%$

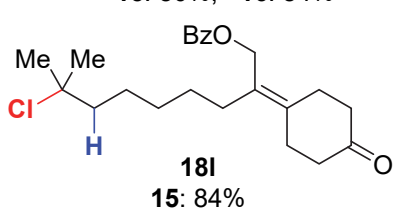

Scheme 11 Hydrochlorination of alkenes with phosphonium salt

By using the combination of this phosphonium salt and a lewis acid, the hydrochlorination was accomplished with Markovnikov addition of $\mathrm{HCl}$ under mild reaction conditions. The reactions tolerated diverse functionality, including alkyne (18a, 18b), indole (18c), pyridine (18d), thiophene (18e), furan (18f), ester (18g) and some protecting and easy leaving groups $(\mathbf{1 8 h} \sim \mathbf{1 8 j}) \quad$ (Scheme 11). 1,1-Disubstituted (18k) and tri-substituted (18l) alkenes could be selected to realize the hydrochlorination over an alkene in $\alpha, \beta$-unsaturated system as well as a tetrasubstituted alkene.

Moreover, this hydrochlorination also showed great chemo-selectivity when using polyenes $(19 \mathbf{a} \sim 1$ 19d). Mono-hydrochlorinations at the terminal olefins was obtained with great selectivity and reactivity (Scheme 12). No products with $\mathrm{HCl}$ adding to internal double bond were observed.

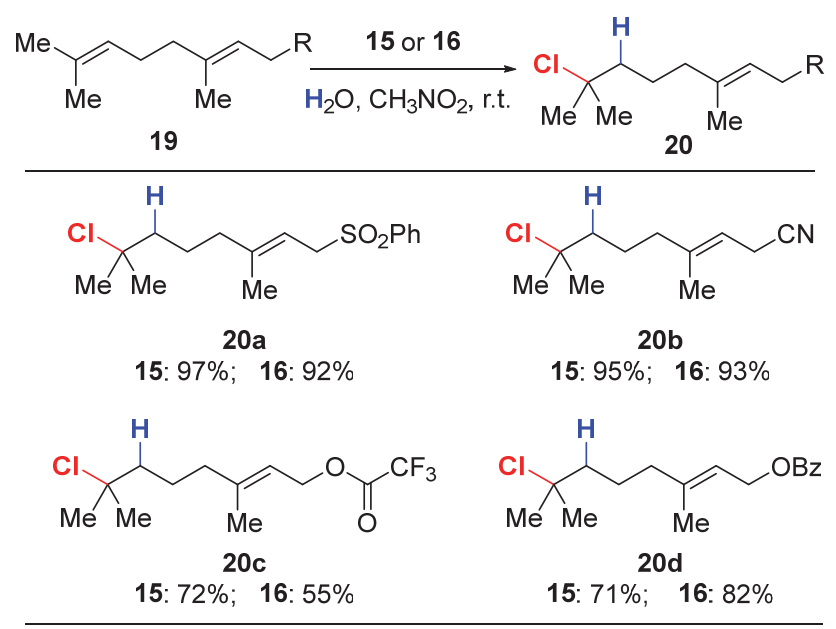

Scheme 12 Hydrochlorination of polyenes with phosphonium salt

In terms of the mechanism of this efficient hydrochlorination of alkenes, they proposed that reagent 15 would undergo hydrolysis to form the active species $\mathbf{2 1}$ under wet solvent (Scheme 13). They thought $\mathrm{HCl}$ coordination to the reagent is critical for the observed selectivity and reactivity, and it is simpler than in situ generation of $\mathrm{HCl}$.<smiles>ClP(CCP(Cl)P(Cl)[AsH2])c1ccccc1</smiles>

15

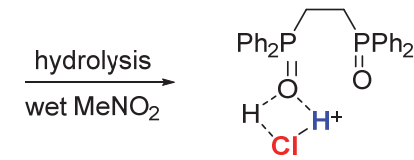

21 scheme 13 Active reagent and the mechanism of material hydrochlorination

\subsection{Anti-Markovnikov hydrochlorination of alkenes}

Despite great breakthroughs have been made for Markovnikov hydrochlorination, the direct anti-Markovnikov addition of $\mathrm{HCl}$ to alkenes remains an unsolved problem until 2014. By using a photoredox catalyst in conjunction with a redox-active hydrogen atom donor, Nicewicz and coworkers $^{[20]}$ reported the direct anti-Markovnikov addition of $\mathrm{HCl}$ to styrenes for the first time (Scheme 14). Two 
methods have been described to realize the antiMarkovnikov hydrochlorination of styrenes using 9-mesityl-10-methylacridinium (22) as the catalyst.
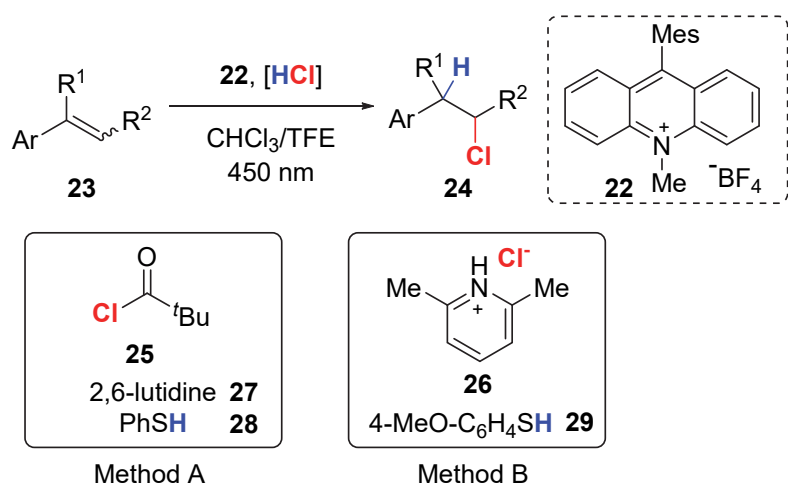

Scheme 14 Two methods of anti-Markovnikov hydrochlorination

One of the methods is involved in using anhydrous hydrogen chloride, which is generated in situ from pivaloyl chloride (25) and 2,2,2-trifluoroethanol (TFE) (Method A). The desired anti-Markovnikov hydrochlorination was successfully achieved with thiophenol (28) as the co-catalyst for generating the redox-active hydrogen atom donor. With this method, hydrochlorination of styrenes with electronwithdrawing groups gave moderate yield with good regioselectivity. However, substrates with electron-donating groups provided lower yields and favored the undesired Markovnikov products.

To increase the reactivity and regioselectivity, they developed alternative method by using combination of 2,6lutidinium hydrochloride (26) and 4-methoxythiophenol (29) (Method B). The nucleophile counterion plays a critical role by ensuring high reactivity, with 2,6-lutidinium salts typically furnishing the best results. The nature of the redox-active hydrogen atom donor is also important, with 4-methoxythiophenol (29) providing the best reactivity. By using this method, high reactivity and regioselectivity were obtained with various alkenes, including electron-donating styrenes, terminal alkenes, and tri-substituted alkenes (Scheme 15).

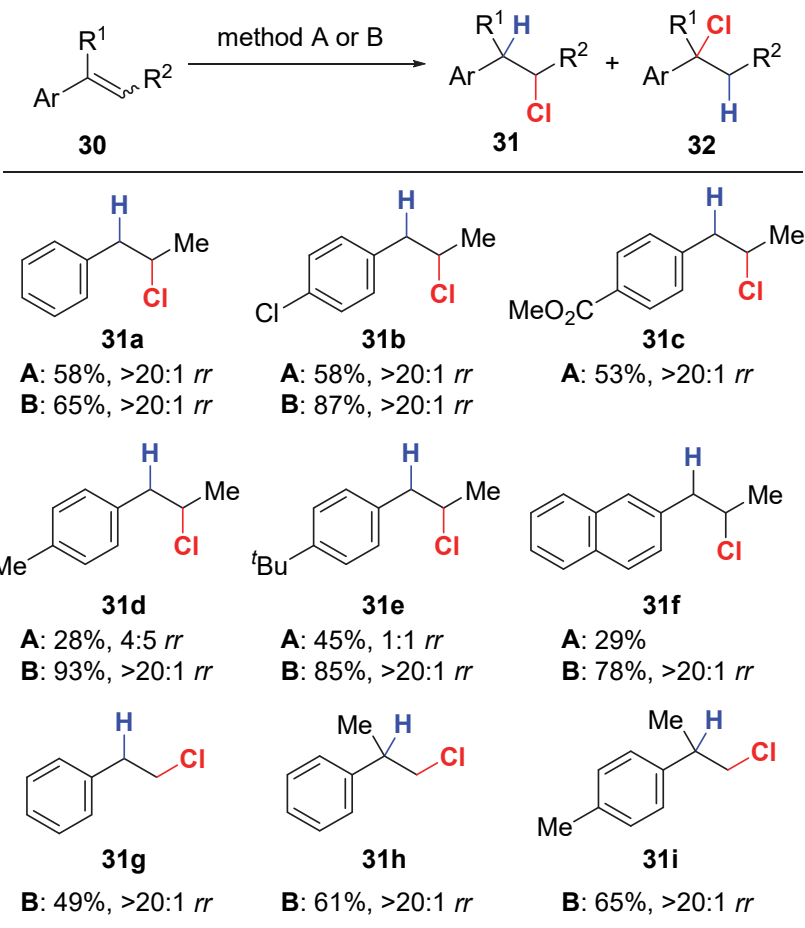

rr (regioselectivity ratio): the ratio between $\mathbf{3 1}$ and 32 .

Scheme 15 Select examples of the anti-Markovnikov hydrochlorination

They also presented a proposed catalytic mechanism for the anti-Markovnikov hydrochlorination. The catalytic cycle began with electronic excitation of photoredox catalyst 22 by visible light (450 $\mathrm{nm})$ (Scheme 16). The excited

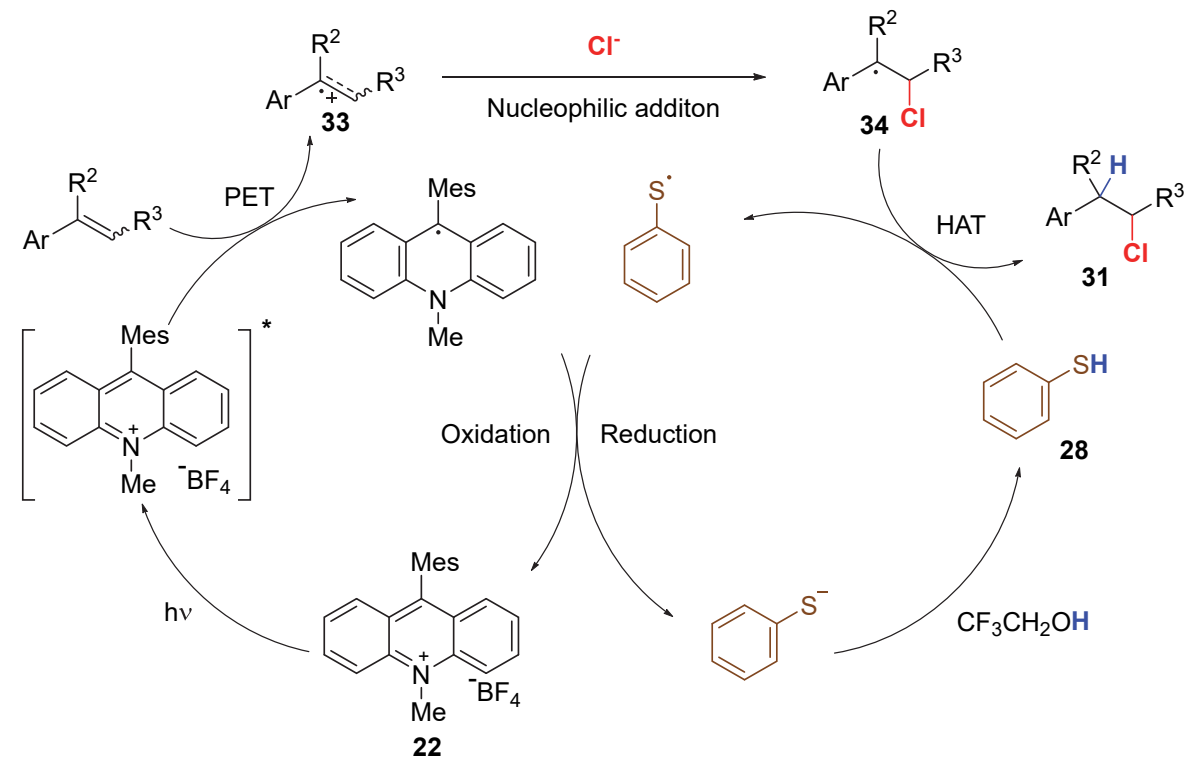

Scheme 16 Proposed catalytic cycle for the anti-Markovnikov hydrochlorination of alkenes 
state catalyst was quenched by photoinduced electrontransfer (PET) from the alkene, and the corresponding alkene radical cation $\mathbf{3 3}$ was formed. Nucleophilic attack to this alkene intermediate by the chlorine produced the more stable benzylic carbon-centered radical. Hydrogen atom transfer (HAT) from thiol $\mathbf{2 8}$ to the radical intermediate $\mathbf{3 4}$ provided the desired anti-Markovnikov product $\mathbf{3 1}$ along with the forming of thiyl radical. The effective turnover of the photoredox catalyst by oxidation was believed to be coupled to the reduction of the thiyl radical. 2,2,2Trifluoroethanol (TFE) is the proton source to convert latent thiolate to the active hydrogen atom donor thiol

\section{Metal-catalyzed hydrochlorination of alkenes}

Transition metal catalysis has attracted considerable research interest during the past three decades. With its prominent advantages including higher efficiency, precise controlled selectivity and better sustainability, it has impressed both the academia and industries. Hydrochlorination of alkenes catalyzed by transition metal has been developed to synthesize the chlorides with high efficiency.

In 1991, Alper and co-workers ${ }^{[21]}$ reported that platinum(II) carbonyl derivatives were able to promote the hydrochlorination of alkenes. With the addition of gaseous $\mathrm{HCl}$, a number of symmetrical (cyclohexene, norbornene), terminal (1-decene, propylene, styrene) and internal olefins were converted to the Markovnikov chloride products by using $\mathrm{PtCl}_{2}\left(\mathrm{C}_{6} \mathrm{H}_{10}\right)(\mathrm{CO})$ as catalyst (Scheme 17, a). Hydrochlorination of deuterated cyclohexene $(d-35)$ gave the $s y n$-addition product 36, which was in contrast with the results of the hydrochlorination of the same substrate in the glacial acetic acid and with anhydrous hydrogen chloride. $^{[22]}$

(a)

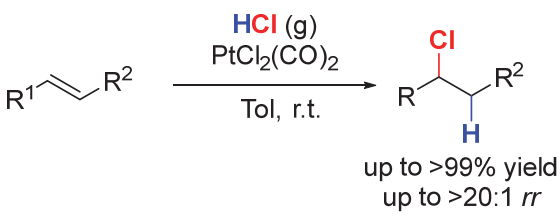

(b)<smiles>[2H]C1=CC([2H])([2H])CCC1</smiles>

35

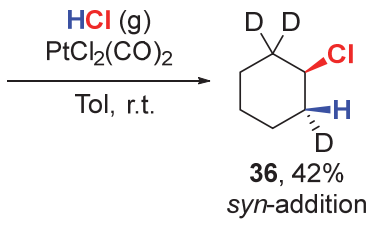

Scheme 17 Pt-catalyzed hydrochlorination of alkenes

Transition-metal catalyzed hydrochlorination without acid was not realized until Sigman group ${ }^{[23]}$ developed a Pd-catalyzed hydrochlorination of styrenes in 2007. With $\mathrm{Pd}(\mathrm{MeCN})_{2} \mathrm{Cl}_{2}$ as catalyst, hydrochlorination of electronpoor styrene provided the desired products in moderate yield (38a, 38b, Scheme 18). However, no chloride product was observed when electron-rich alkene was used, and the corresponding benzylic ether 38c was formed in high yield. The reason was that the forming chloride could further undergo $\mathrm{S}_{\mathrm{N}} 1$ reaction to form benzylic ethers due to the existence of alcohol in the reaction system.
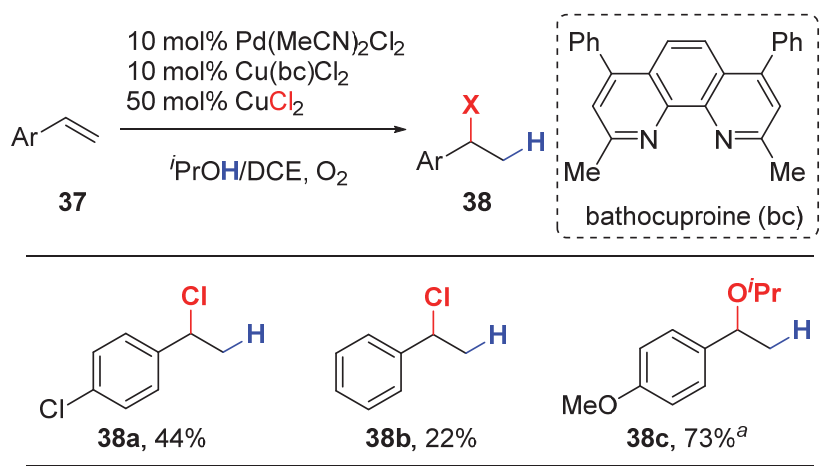

a using $5 \mathrm{~mol} \% \mathrm{Pd}(\mathrm{MeCN})_{2} \mathrm{Cl}_{2}, 5 \mathrm{~mol} \% \mathrm{Cu}(\mathrm{bc}) \mathrm{Cl}_{2}, 20 \mathrm{~mol} \% \mathrm{CuCl}_{2}$

Scheme 18 Pd-catalyzed hydrochlorination of styrenes

On the basis of their mechanism studies, the mechanism was proposed as shown in Scheme 19. Initially, Pd(II)hydride 39 was formed via an alcohol oxidation, followed by coordination of the double bond to Pd. Insertion of the double bond into the $\mathrm{Pd}(\mathrm{II})$-hydride gave more stable intermediate 41. The observed chlorides 38 were formed either via reductive elimination or nucleophilic attack on 41. The forming $\operatorname{Pd}(0)$ species 42 were subsequently reoxidized by $\mathrm{O}_{2}$ and/or $\mathrm{CuCl}_{2}$ to regenerate the active $\mathrm{Pd}(\mathrm{II})$ catalyst.

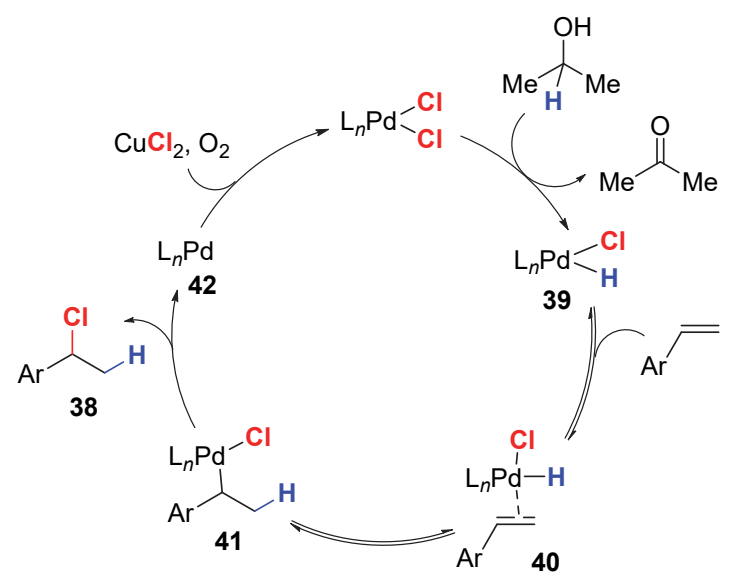

Scheme 19 Mechanism for Pd-catalyzed hydrochlorination of styrenes

Albeit this Pd-catalyzed hydrochlorination provided the desired chlorides under neutral conditions, the addition could only be conducted with styrenes. Moreover, the benzylic chloride adducts were isolable only for electronpoor arenes. In 2008, Carreira and co-workers ${ }^{[24]}$ reported the Co-catalyzed hydrochlorination of aliphatic alkenes under mild conditions by using $\mathrm{TsCl}$ as $\mathrm{Cl}$ source (Scheme 20). Hydrochlorination of various alkenes worked well and provided the corresponding products in high yields with great regioselectivity $(\mathbf{4 5 a} \sim \mathbf{4 5 f})$. It is worth mentioning that this transformation tolerated a range of functional 
groups including acid sensitive species $(\mathbf{4 5 e}, \mathbf{4 5 f})$.

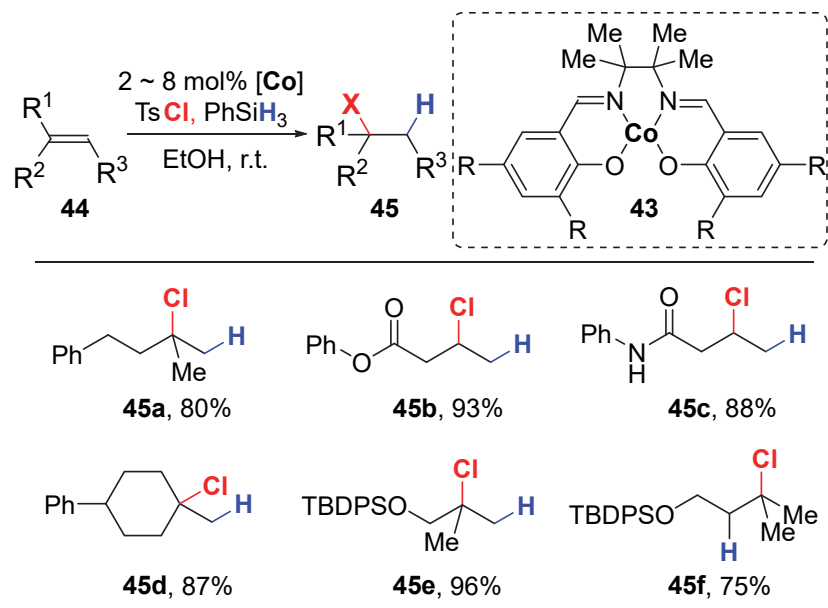

Scheme 20 Co-catalyzed hydrochlorination of unactivated alkenes

Their group ${ }^{[25]}$ had detailed mechanism studies for the Co-catalyzed hydrohydrazination and hydroazidation reactions. On basis of these research, they proposed that the catalytic cycle was initiated by formation of a Co-hydride complex, followed by coordination of alkenes to Co (Scheme 21). Insertion of the double bond into the Co(III)-hydride provided organocobalt intermediate 48, which was converted into the chloride product through a free-radical intermediate 49.

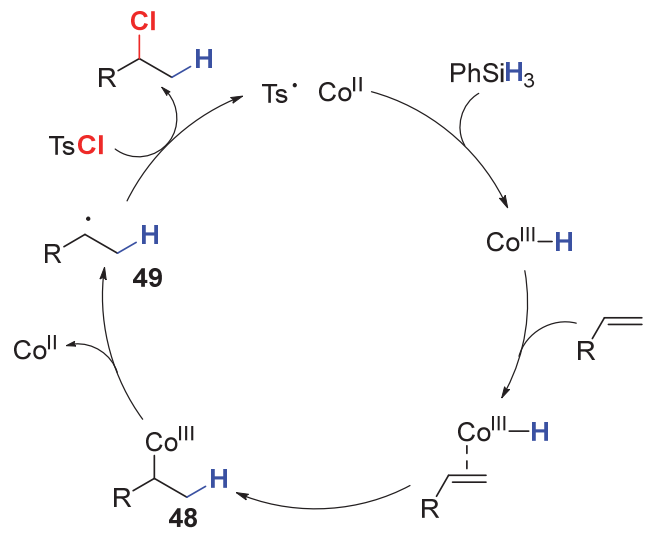

Scheme 21 Mechanism for Co-catalyzed hydrochlorination

\section{Conclusion and outlook}

Since the first reported hydrochlorination of alkenes using anhydrous hydrogen chloride, many methods have been described to improve this reaction. Although some preliminary progresses have been made in the hydrochlorination of olefins over the years, there are still great limitations. Hydrochlorination is usually through carbocation intermediates which lead to Markovnikov addition. It is still difficult to get anti-Markovnikov product. Moreover, asymmetric hydrochlorination of olefins has not been realize yet. Therefore, the development of enantioselectivity and regioselectivity of a wide range of alkenes would be a considerable breakthrough in the field.

We hope that this review can provide helpful overview of the current state of hydrochlorination. We anticipate that the problems mentioned above will be solved in the near future after further investigations. Overall, with the increasing requirement for chiral organochlorides, developing a novel, efficient and easy to operate catalytic system to achieve stereoselective, regioselective and enantioselective hydrochlorination of alkenes should become valuable research direction.

\section{References}

[1] (a) Kyne, S. H.; Lefèvre, G.; Ollivier, C.; Petit, M.; Cladera, C. A. R.; Fensterbank, L. Chem. Soc. Rev. 2020, 49, 8501.

(b) Liu, Q.; Zhang, L.; Mo, F. Acta Chim. Sinica 2020, 78, 1297 (in Chinese).

(刘谦益, 张雷, 莫凡洋, 化学学报, 2020, 78, 1297.)

(c) Togo, H. Advanced Free Radical Reactions for Organic Synthesis, Elsevier, Amsterdam, 2004

[2] Carey, F. A.; Sundberg, R. J. Advanced Organic Chemistry, 5th ed., Springer, New York, 2007.

[3] For reviews, see: (a) Cheng, L.; Zhou, Q.-L. Acta Chim. Sinica 2020, 78, 1017 (in Chinese).

(程否, 周其林, 化学学报, 2020, 78, 1017.)

(b) Zweig, J. E.; Kim, D. E.; Newhouse, T. R. Chem. Rev. 2017, 117, 11680.

(c) Liu, N.-W.; Liang, S.; Manolikakes, G. Synthesis 2016, 48, 1939.

(d) Terao, J.; Kambe, N. Acc. Chem. Res. 2008, 41, 1545.

(e) Rudolph, A.; Lautens, M. Angew. Chem., Int. Ed. 2009, 48, 2656.

For select papers, see: (f) Yao, D.; Zhang, J.; Xu, L. Chin. J. Org. Chem. 2020, 40, 1673 (in Chinese).

(姚丹丹, 张金利, 徐亮, 有机化学, 2020, 40, 1673.)

(g) Ma, D.; Niu, S.; Zhao, J.; Jiang, X.; Jiang, Y.; Zhang, X.; Sun, T. Chin. J. Chem. 2017, 35, 1661.

(h) Wang, X.; Wang, S. L.; Xue, W. C.; Gong, H. G. J. Am. Chem. Soc. 2015, 137, 11562.

(i) Gong, T.; Jiang, Y.; Fu, Y. Chin. Chem. Lett. 2014, 25, 397.

(j) Atack, T. C.; Cook, S. P. J. Am. Chem. Soc. 2012, 138, 6139.

(k) Dudnik, A. S.; Fu, G. C. J. Am. Chem. Soc. 2012, 134, 10693.

[4] (a) Kohlmeyer, C.; Schafer, A.; Huy, P. H.; Hilt, G. ACS Catal. 2020, 10, 11567

(b) Mohite, A. R.; Phatake, R. S.; Dubey, P.; Agbaria, M.; Shames, A. I.; Lemcoff, N. G.; Reany, O. J. Org. Chem. 2020, 85, 12901.

(c) Zheng, D.; Zhou, A.; Zhu, X.; Zheng, H.; Sun, X. Chin. J. Org. Chem. 2016, 36, 137 (in Chinese).

(郑大贵，周安西，祝显虹，郑洪富，孙向前，有机化学，2016, 36, 137.)

(d) Huy, P. H.; Motsch, S.; Kappler, S. M. Angew. Chem., Int. Ed. 2016, 55, 10145.

(e) Vanos, C. M.; Lambert, T. H. Angew. Chem., Int. Ed. 2011, 50, 12222 .

[5] King, S. M.; Ma, X.; Herzon, S. B. J. Am. Chem. Soc. 2014, 136, 6884.

[6] (a) Yu, P.; Bismuto, A.; Morandi, B. Angew. Chem., Int. Ed. 2020 , 59, 2904.

(b) Zeng, X.; Liu, S.; Hammond, G. B.; Xu, B. ACS Catal. 2018, 8 , 904.

(c) Derosa, J.; Cantu, A. L.; Boulous, M. N.; O’Duill, M. L.; Turnbull, J. L.; Liu, Z.; De La Torre, D. M.; Engle, K. M. J. Am. Chem. Soc. 2017, 139, 5183.

(d) Zeng, X.; Lu, Z.; Liu, S.; Hammond, G. B.; Xu, B. J. Org. Chem. 2017, 82, 13179.

(e) Xu, C.; Ma, C.; Xiao, F.; Chen, H. Chin. Chem. Lett. 2016, 27, 
1683.

[7] For select reviews, see: (a) Guillemard, L.; Kaplaneris, N.; Ackermann, L.; Johansson, M. J. Nat. Rev. Chem. 2021, 5, 522.

(b) Petrone, D. A.; Ye, J.; Lautens, M. Chem. Rev. 2016, 116, 8003.

(c) Liu, W.; Groves, J. T. Acc. Chem. Res. 2015, 48, 1727.

For select papers, see: (d) Fawcett, A.; Keller, M. J.; Herrera, Z.; Hartwig, J. F. Angew. Chem., Int. Ed. 2021, 60, 8276.

(e) Herron, A. N.; Liu, D.; Xia, G.; Yu, J.-Q. J. Am. Chem. Soc. 2020, 142, 2766.

(f) Zhu, Y.; Shi, J.; Yu, W. Org. Lett. 2020, 22, 8899.

(g) Li, G.; Dilger, A. K.; Cheng, P. T.; Ewing, W. R.; Groves, J. T. Angew. Chem., Int. Ed. 2018, 57, 1251.

(h) Quinn, R. K.; Kçnst, Z. A.; Michalak, S. E.; Schmidt, Y.; Szklarski, A. R.; Flores, A. R.; Nam, S.; Horne, D. A.; Vanderwal, C. D.; Alexanian, E. J. J. Am. Chem. Soc. 2016, 138, 696.

[8] Smith, M. B.; March, J. March's Advanced Organic Chemistry, John Wiley and Sons, New York, 2001.

[9] (a) Fahey, R. C.; McPherson, C. A. J. Am. Chem. Soc. 1971, 93, 2445.

(b) Stille, J. K.; Sonnenberg, F. M.; Kinstle, T. H. J. Am. Chem. Soc. 1966, $88,4922$.

(c) Brown, H. C.; Rei, M.-H. J. Org. Chem. 1966, 31, 1090.

(d) Dewar, M. J. S.; Fahey, R. C. J. Am. Chem. Soc. 1963, 85, 2245.

(e) Ecke, G. G.; Cook, N. C.; Whitmore, F. C. J. Am. Chem. Soc. 1950, 72, 1511.

(f) Schmerling, L. J. Am. Chem. Soc. 1946, 68, 195.

(g) Whitmore, F. C.; Johnston, F. J. Am. Chem. Soc. 1933, 55, 5020.

[10] Onitsuka, S.; Jin, Y. Z.; Shaikh, A. C.; Furuno, H.; Inanaga, J. Molecules 2012, 17, 11469.
[11] Jin, Y. Z.; Yasuda, N.; Furuno, H.; Inanaga, J. Tetrahedron Lett. 2003, 44, 8765 .

[12] Ballini, R.; Bosica, G.; Parrini, M. Tetrahedron Lett. 1998, 39, 7963.

[13] (a) Kropp, P. J.; Daus, K. A.; Tubergen, M. W.; Kepler, K. D.; Wil-son, V. P.; Craig, S. L.; Baillargeon, M. M.; Breton, G. W. J. Am. Chem. Soc. 1993, 115, 3071.

(b) Kropp, P. J.; Daus, K. A.; Crawford, S. D.; Tubergen, M. W.; Kepler, K. D.; Craig, S. L.; Wilson, V. P. J. Am. Chem. Soc. 1990, 112,7433 .

[14] de Mattos, M. C. S.; Sanseverino, A. M. Synth. Commun. 2001, 30, 1975.

[15] Tanemura, K. Tetrahedron Lett. 2018, 59, 4293.

[16] Boudjouk, P.; Kim, B. K.; Han, B. H. Synth. Commun. 1996, 26 , 3479.

[17] Yadav, V. K.; Babu, K. G. Eur. J. Org. Chem. 2005, 2005, 452.

[18] Liang, S.; Hammond, G. B.; Xu, B. Green. Chem. 2018, 20, 680.

[19] Schevenels, F. T.; Shen, M.; Snyder, S. A. J. Am. Chem. Soc. 2017, 139,6329 .

[20] Wilger, D. J.; Grandjean, J. M. M.; Lamment, T. R.; Nicewicz, D. A. Nat. Chem. 2014, 6, 720 .

[21] Alper, H.; Huang, Y. Organometallics 1991, 10, 1665.

[22] Fahey, R. C.; Monahan, M. W.; Mcphersons, C. A. J. Am. Chem. Soc. 1970, 92, 2816.

[23] Podhajsky, S. M.; Sigman, M. S. Organometallics. 2007, 26, 5680.

[24] Gaspar, B.; Carreira, E. M. Angew. Chem., Int. Ed. 2008, 47, 5758.

[25] Waser, J.; Gaspar, B.; Nambu, H.; Carreira, E. M. J. Am. Chem. Soc. 2006, 128, 11693. 